Article

\title{
Generating a High-Precision True Digital Orthophoto Map Based on UAV Images
}

\author{
Yu Liu ${ }^{1}$, Xinqi Zheng ${ }^{1, *(1)}$, Gang Ai ${ }^{1, *}$, Yi Zhang ${ }^{1}$ and Yuqiang Zuo ${ }^{2}$ \\ School of Information Engineering, China University of Geoscience Beijing, Beijing 100083, China \\ China Land Surveying and Planning Institute, Beijing 100035, China \\ * Correspondence: zhengxq@cugb.edu.cn (X.Z.); aigang@cugb.edu.cn (G.A.); Tel.: +86-010-8232-2116 (X.Z.)
}

Received: 26 June 2018; Accepted: 20 August 2018; Published: 21 August 2018

\begin{abstract}
Unmanned aerial vehicle (UAV) low-altitude remote sensing technology has recently been adopted in China. However, mapping accuracy and production processes of true digital orthophoto maps (TDOMs) generated by UAV images require further improvement. In this study, ground control points were distributed and images were collected using a multi-rotor UAV and professional camera, at a flight height of $160 \mathrm{~m}$ above the ground and a designed ground sample distance (GSD) of $0.016 \mathrm{~m}$. A structure from motion (SfM), revised digital surface model (DSM) and multi-view image texture compensation workflow were outlined to generate a high-precision TDOM. We then used randomly distributed checkpoints on the TDOM to verify its precision. The horizontal accuracy of the generated TDOM was $0.0365 \mathrm{~m}$, the vertical accuracy was $0.0323 \mathrm{~m}$, and the GSD was $0.0166 \mathrm{~m}$. Tilt and shadowed areas of the TDOM were eliminated so that buildings maintained vertical viewing angles. This workflow produced a TDOM accuracy within $0.05 \mathrm{~m}$, and provided an effective method for identifying rural homesteads, as well as land planning and design.
\end{abstract}

Keywords: unmanned aerial vehicle; structure from motion; multi view stereo; digital surface model; true digital orthophoto map

\section{Introduction}

In recent years, low-altitude remote sensing unmanned aerial vehicle (UAV) technology has been widely adopted in many fields, and it has become a key spatial data acquisition technology. The application of UAV low-altitude remote sensing images is a recent trend in real estate registration. Traditional manual measurements of both developed and undeveloped land areas involves substantial time, effort, and costs. Additionally, traditional aerial photogrammetry techniques are time-consuming and the costs of flying are high. For small study areas, UAV remote sensing has many advantages over traditional manual measurements and aerial photogrammetry. It is flexible, low-cost, safe, reproducible, and reliable, with low flight heights, high precision, and large-scale measurements that save on manpower and material costs [1-6].

A digital orthophoto map (DOM) is an image obtained by vertical parallel projection of a surface, and has the geometric accuracy of a map and visual characteristics of an image. A true digital orthophoto map (TDOM) is an image dataset that produces a surface image by vertical projection, eliminating the projection differences of standard DOMs, and retaining the correct positions of ground objects and features. TDOMs ensure the geometric accuracy of features and maps [5-8]. The most notable difference between a TDOM and a traditional DOM is that a TDOM performs ortho-rectification and analyzes the visibility of features. Moreover, a conventional orthophoto uses a digital elevation model (DEM), whereas a true orthophoto uses a digital surface model (DSM). Thus, TDOMs are rich in color, and simplify the identification of textural patterns [7-15]. 
Many previous studies have analyzed UAV images. In a study of DOM accuracy, Gao et al. [16] investigated ancient earthquake surface ruptures, and obtained both a DEM and a DOM with resolutions of $0.065 \mathrm{~m}$ and $0.016 \mathrm{~m}$, respectively. Additionally, Uysal et al. [17] obtained $0.062 \mathrm{~m}$ overall vertical accuracy from an altitude of $60 \mathrm{~m}$. However, production workflow and methods can influence the accuracy of orthophotos. Westoby et al. [18] outlined structure from motion (SfM) photogrammetry; a revolutionary, low-cost, user-friendly, and effective tool. Since then, common production workflows have used SfM and multi-view stereopsis techniques to produce DSMs and DOMs, and to build 3D geological models [7,14,19-23]. As for orthorectification, Zhu et al. [24] proposed an object-oriented true ortho-rectification method.

Unmanned aerial vehicle (UAV) low-altitude remote sensing has a wide range of applications. It allows for the rapid remote surveying of inaccessible areas, and can be used to monitor active volcanos, geothermally active areas, and open-pit mines [25-27]. It can also be used to map landslide displacements $[4,28,29]$ and to study glacial landforms [30-32], precision agriculture $[33,34]$, archaeological sites [35], landscapes [36], and ecosystems [13].

However, previous research on the use of TDOMs in remote sensing is lacking in some areas. Therefore, our study aims to improve TDOM production using UAV images in the following ways: (1) The accuracy of TDOMs in current research is still unsatisfactory in some applications, such as determining the boundaries of rural housing sites and precision agriculture. We outlined a structure from motion, revised DSM and multi-view image texture compensation workflow to generate a high-precision TDOM accuracy within $0.05 \mathrm{~m}$. (2) We used DSM to generate DOM, we artificially edited the DSM in the point cloud for obliquely shaded areas. This technique may help to eliminate the tilt and shadow in DOMs after DSMs have been revised. (3) For the oblique shielding area, we used a multi-view image compensation method to improve texture compensation [37]. (4) We vectorized homestead buildings in the test area to demonstrate its practical application.

In this study, we use Miyun District in Beijing, China as the research area, collect UAV aerial data, and introduce the structure from motion (SfM) algorithm to generate point clouds, DSMs, and DOMs. For houses with partial DOM tilt problems, we use a revised DSM and multi-view image compensation to eliminate tilt and generate the TDOM. The complete workflow of the study is shown in Figure 1. We then validate and discuss the generated point clouds, DSM, and TDOM, and propose a high-precision mapping method for UAV remote sensing, which may be applicable to real estate registration in China and elsewhere.

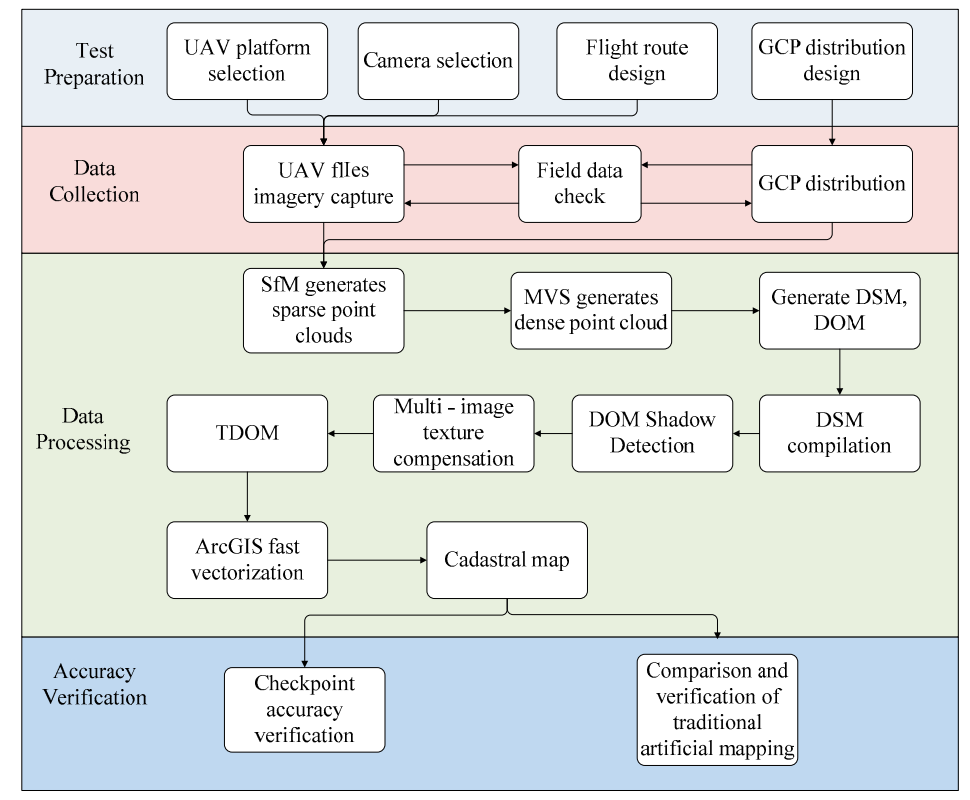

Figure 1. Workflow schematic of the study. 


\section{Study Area}

The study area is located in Xishaoqu Village, Miyun County, in the northeast of Beijing, China $\left(40.2768151^{\circ} \mathrm{N}\right.$ and $\left.116.9145208^{\circ} \mathrm{E}\right)$. An overview of the study area, which measures approximately $0.3 \mathrm{~km}^{2}$ and consists predominantly of rural homesteads and single-story bungalows is shown in Figure 2, The village is flat and surrounded by farmland. The selected UAV flight area is extended to the north and south in a rectangular shape. The maximum and minimum altitudes were $140 \mathrm{~m}$ and $120 \mathrm{~m}$, respectively, with an average altitude of $130 \mathrm{~m}$. Test areas A and B in Figure 2 were selected for study.
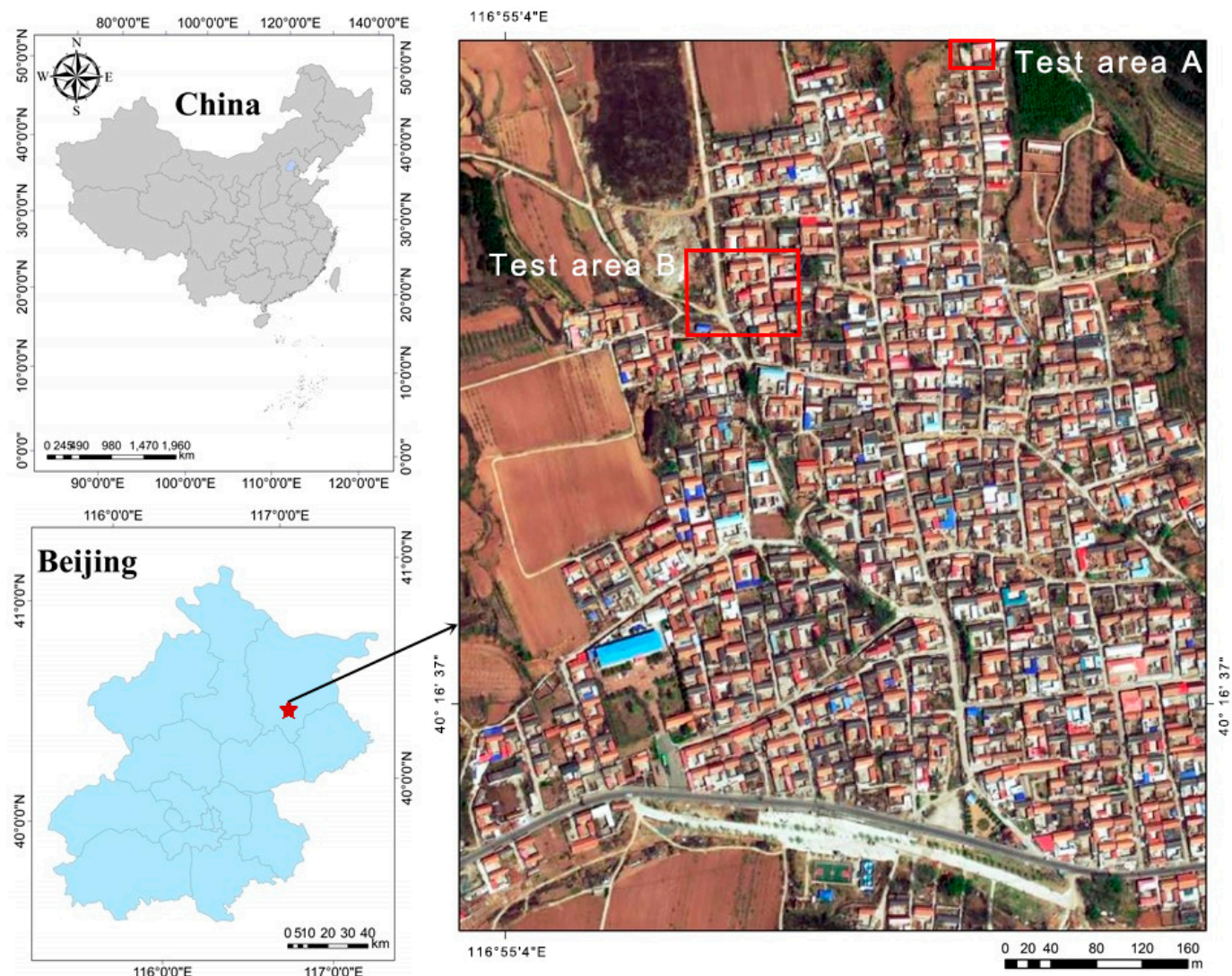

Figure 2. Overview of the study area.

\section{Materials and Methods}

\subsection{UAV Flight}

\subsubsection{UAV and Digital Camera}

The Dà-Jiāng Innovations (DJI) S900 UAV (Shenzhen, Guangdong, China, https:/ / www.dji.com/cn) used in this study was a six-rotor flight platform, which is a highly portable, powerful aerial system for photogrammetry. The S900's main structural components are composed of light carbon fiber, making it lightweight, but strong and stable. It weighs $3.3 \mathrm{~kg}$, and has a maximum takeoff weight of $8.2 \mathrm{~kg}$ when carrying a pan/tilt/zoom (PTZ) camera. It can fly for up to $18 \mathrm{~min}$ with a payload of $6.8 \mathrm{~kg}$ and a $6 \mathrm{~S}$ $12,000 \mathrm{mAh}$ battery on a breezeless day. In the test, we flew for approximately $12 \mathrm{~min}$.

The UAV was equipped with a Sony A7r digital camera providing 36 million pixels and a resolution of $7360 \times 4912$ pixels. It had a sensor size of $35.9 \times 24 \mathrm{~m}$, a Vario-Tessar T* FE 24-70 mm F4 ZA OSS(ZEL2470Z) lens, a shutter time of $1 / 1600 \mathrm{~s}$, an aperture of $\mathrm{f6.3}$, and an ISO of 250 . The camera was equipped with the DJI S900 UAV to collect image data, as shown in Figure 3a. The camera weight 
was $998 \mathrm{~g}$, the focus length was set to $50 \mathrm{~mm}$, and the field of view (FOV) was $46.7^{\circ}$, calculated using Equation (1):

$$
F O V=2 \times \tan ^{-1}(d / 2 f)
$$

where $d$ is the diagonal length of the sensor size and $f$ is the focus length. Camera calibration was performed as part of the SfM process by Pix $4 \mathrm{~d}$, which calculated the initial and optimized values of interior orientation parameters: initial focal length $=50 \mathrm{~mm}$, optimized $=49.65 \mathrm{~mm}$; principal point coordinates $x=17.5,17.55 \mathrm{~mm} ; y=11.679,11.682 \mathrm{~mm}$, radial distortion $=-0.048,-0.189 \mathrm{~mm}$, and tangential distortion $=0,0 \mathrm{~mm}$.

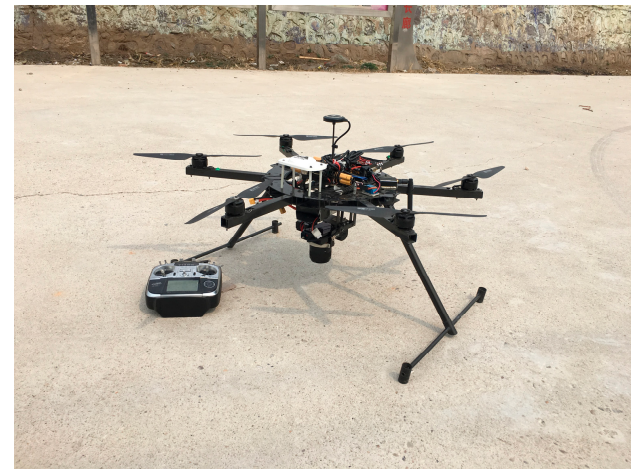

(a)

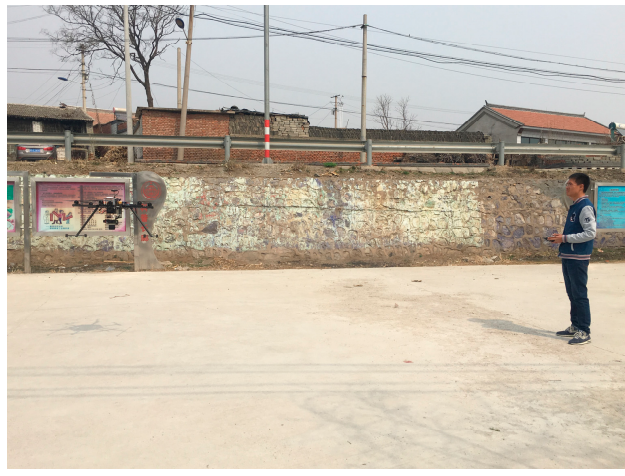

(b)

Figure 3. Photographs of (a) the DJI S900 UAV equipped with Sony A7r camera and (b) the UAV taking off.

\subsubsection{Ground Control Point (GCP) Layout}

We used ground control point (GCP) data obtained by continuously operating reference station (CORS) method of georeferencing the data. Compared with the real-time kinematic global positioning satellite (RTK-GPS) method, the CORS-GPS method is more stable and reliable, which improves the accuracy to within $0.02 \mathrm{~m}$ [38]. Before performing field observations, we used Google Earth to establish 15 control points and 10 checkpoints that were randomly distributed within the village survey area: along the main road, at road interchanges, at housing inflection points, and in farmland. We used a CORS method to collect GCP data, using the STONEX SC200 high-performance CORS receiver. We established the ground CORS base station, employing a mobile hand-held GPS to measure the coordinates of each control point and checkpoint data. The CORS method used GLONASS and BeiDou GNSS positioning, the root-mean-squared error (RMSE) of the CORS method was within $0.02 \mathrm{~m}$, and the coordinate system was WGS84.

\subsubsection{Flight Plan and Data Collection}

Route planning was completed using the software RockyCapture version 1.22 (http://www.rockysoft.cn) of the DJI UAV system. The survey area was $0.3 \mathrm{~km}^{2}, 701 \mathrm{~m}$ long, and $330 \mathrm{~m}$ wide. The route design comprised two flights, 10 planned routes, and a serpentine line. The flight height was $160 \mathrm{~m}$ above the ground, the designed ground sampling distance (GSD) was $1.6 \mathrm{~cm}$, the planning overlap rate was $80 \%$, the side overlap rate was $60 \%$, the exposure interval was $2 \mathrm{~s}$, and each flight lasted $12 \mathrm{~min}$. Aerial photography was performed under sunny, cloudless, and breezeless weather conditions. A total of 460 images were taken.

\subsection{SfM Algorithm and Point Cloud Generation}

With recent advances in computer vision technology, SfM and multi-view stereo (MVS) algorithms have been successfully applied to UAV image processing to generate high-precision DSMs and DOMs. 
In this study, we used a total of 460 high-precision images and 15 GCPs were obtained from the flight, and the control point data were identified in the images. Using the coordinates assigned by the control point data and the image feature points containing these control points, the software retrieved and matched the same feature points in the two images, restored the position and altitude of each image camera exposure, and the image position in the air, and showed the motion. The software illustrated the trajectory and the 3D position of the ground feature points, which formed a sparse 3D point cloud. Geometric reconstruction based on MVS algorithms can produce more detailed 3D model with 15 GCPs to improve the absolute accuracy of the models. The DSM grid-generated 3D model used a map projection of WGS84 UTM $50 \mathrm{~N}$. The original image was projected onto the DSM, and the image texture was mixed in the overlapping area to produce a digital orthophoto image of the entire area.

We used Pix4Dmapper Pro-Non-Commercial version 2.0.83 (https:/ / pix4d.com) to process the image data. The processing settings were as follows: key points image scale: full; point cloud densification image scale: $1 / 2$ (half image size); point density: optimal; minimum number of matches: 3; matching image pairs: aerial grid or corridor; targeted number of key points: automatic, rematch: automatic; set generate 3D textured mesh; maximum number of triangles: 1,000,000; texture size (pixels): $8192 \times 8192$; point cloud format: LAS; 3D textured mesh format: OBJ. We used an inverse distance weighted (IDW) method to generate DSMs. For DSM filters, we used sharp noise filter and sharp surface smoothing. The following software environment was used: $\mathrm{CPU}=\operatorname{Intel}(\mathrm{R})$ Xeon(R) CPU E3-1240 v5 @3.50 GHz; RAM = 20 GB; GPU = NVIDIA GeForce GTX1060 6 GB; operating system $=$ Windows 10 Pro, 64-bit.

\subsection{DSM Revision}

The DSM contains land cover surface height information, such as ground-level buildings, bridges, and trees. While the DTM represents terrain (land surface) information the DSM represents the land cover surface. Additionally, though DEMs contain height information, normally of the terrain, the DSM is in fact a type of DEM that reflects the surface features of all objects located on the ground, to more accurately and intuitively express geographic information. The DSM can also be modified to restore the tilt of buildings. We used DSM instead of DEM to generate DOM results with more surface information.

We manually classified and edited the generated point cloud to obtain a higher quality DSM, and then used the DSM to generate the DOM in Pix4D. We classified the point clouds to remove vegetation, especially vegetation that exceeded the height of buildings. For the buildings, we referred to the original UAV image or the existing topographic map to modify the boundary of the upper building surface. The boundaries of buildings were manually drawn in point clouds. Figure 4a illustrates how the top surface of each building was drawn by connecting control points. All building heights were higher than the ground surface. In Figure $4 b$, the surrounding ground surface was drawn manually, ensuring a consistent ground level. We regenerated the DSM after drawing these boundaries to enhance their precision and clarity. This had the effect of also improving the accuracy and clarity of the corresponding DOM building boundaries, thereby reducing, or even eliminating, the double-projection phenomenon. Finally, we smoothed and de-noised the DSM, and the high-precision DSM was manually revised for parts of buildings that were heavily sloped and sheltered. 


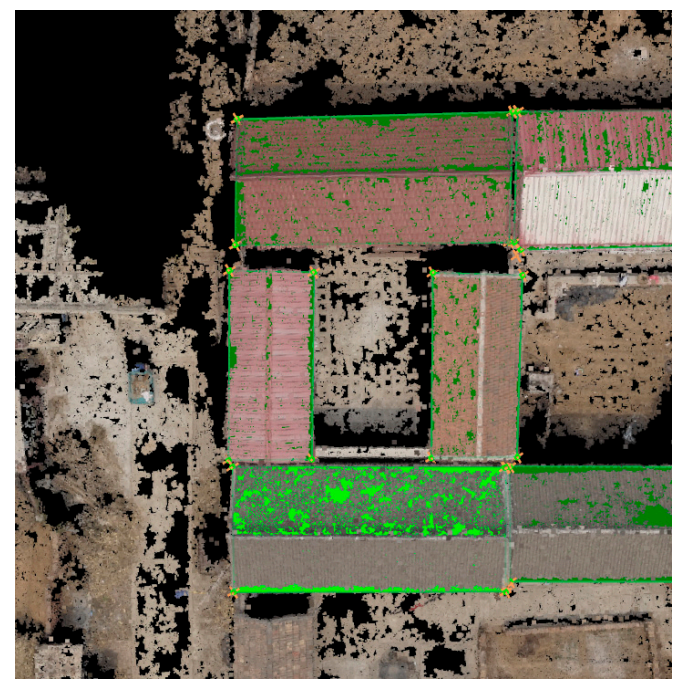

(a)

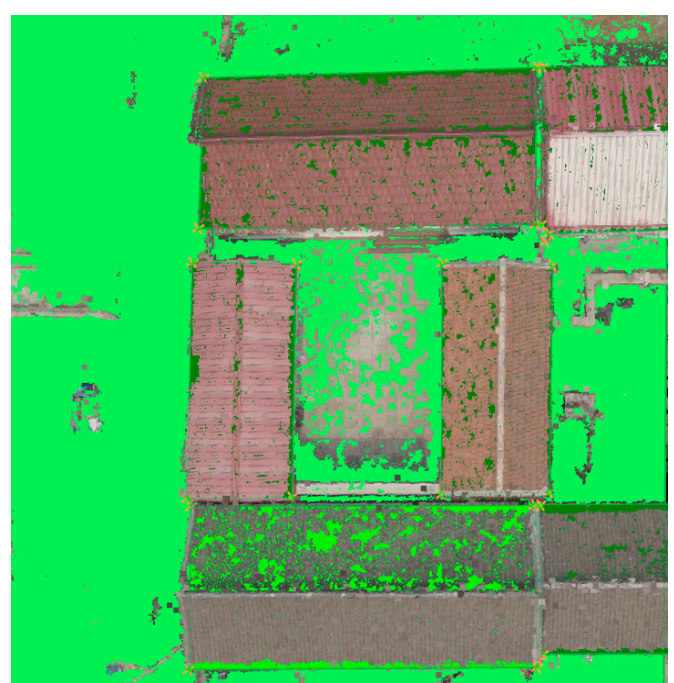

(b)

Figure 4. Images with manually drawn (a) upper building surfaces and (b) ground with a consistent level.

\subsection{Multi-View Image Texture Compensation and TDOM Accuracy Evaluation}

An aerial image was used to transform the central projection into orthograph-projection and to obtain the orthophoto image. An image correction method was used to achieve the correct transformation between the two projections. In this study, we used the digital differential correction method [39]. The principle is to correct the digital image by pixel differentials (i.e., according to the known directional element and DEM of the image, and according to a certain digital model with the control point settlement). The process individually corrected many, very small areas the size of a pixel.

We used manual multi-view image compensation to compensate for the texture of the shaded areas in Pix4D (Figure 5). Masked areas were manually drawn. The adjacent images including the masked area were selected for manual sorting. The sorting method was based on the degree of shading and orthorectification. The masked area camera exposure location for multi-view was shown in Figure $5 b$. Masking area fill-in work was performed one-by-one. To avoid the adjacent image also having a shaded area, occlusion analysis was performed on the first adjacent image after sorting. If the first adjacent image was not shaded, texture compensation was performed; otherwise, texture compensation was not performed, and shadow detection was performed on the next adjacent image. This process was repeated until a suitable adjacent image was obtained to compensate for the texture, and a TDOM was generated with all shadows eliminated. As a result, the buildings maintained a vertical viewing angle, showing only the top of the buildings. 

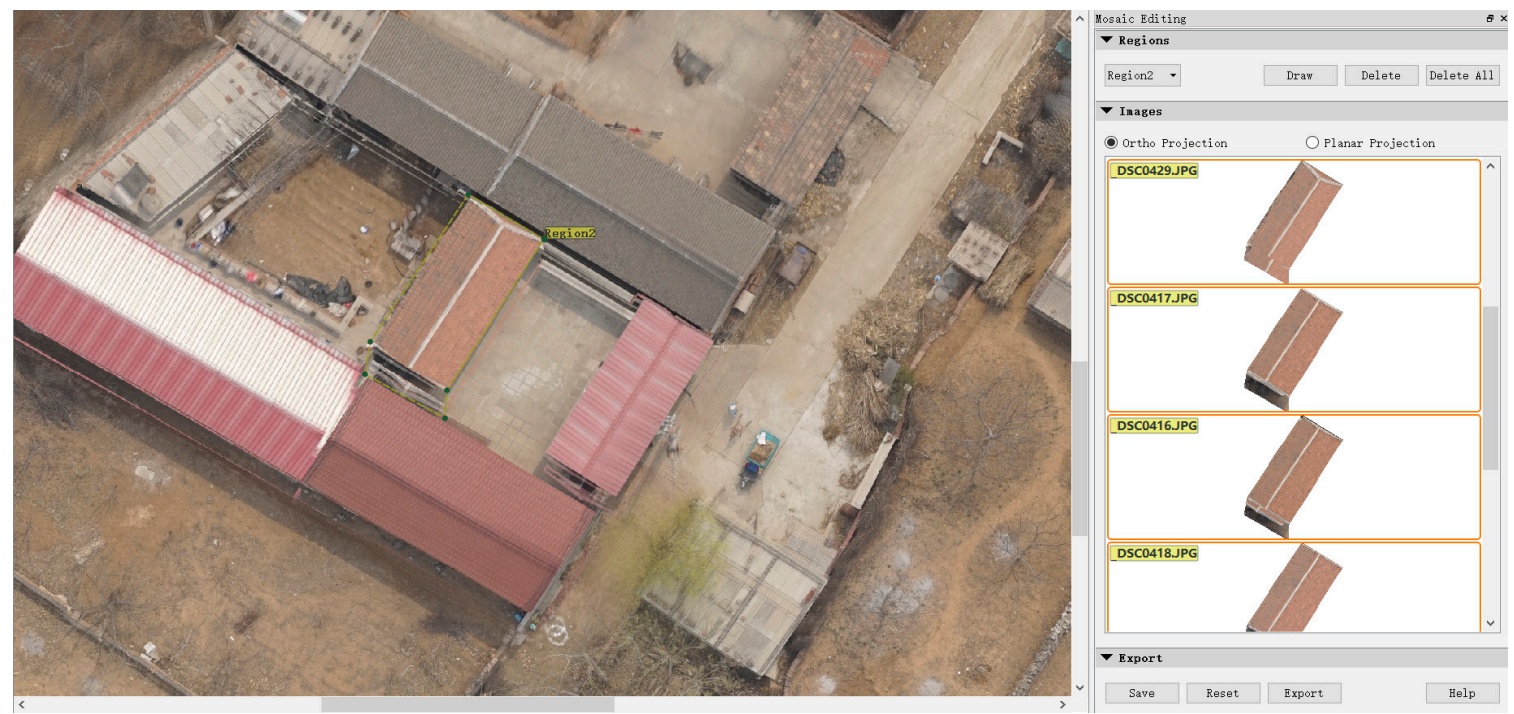

(a)

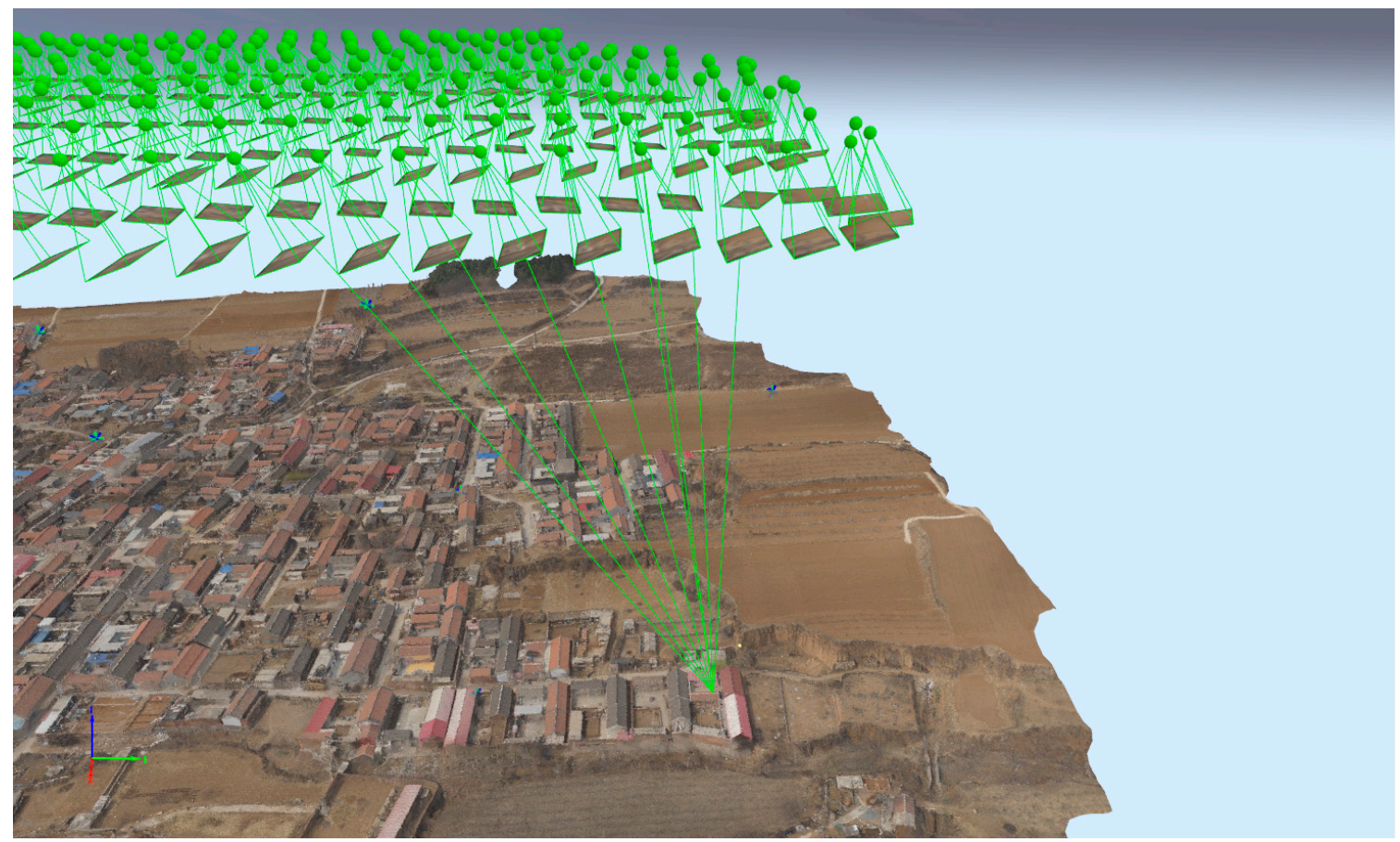

(b)

Figure 5. (a) The multi-view image compensation operation page; and (b) the masked area camera exposure location for multi-view.

After TDOM was generated, we calculated Root Mean Square Error (RMSE) to evaluate the accuracy of the TDOM, we can get the coordinates $(x, y, z)$ of check points which were well seen on the TDOM in Pix4D, and the coordinates $(x, y, z)$ of these check points measured in the field. the $X$-direction error, the $Y$-direction error, the plane error, and the elevation error were calculated using Equations (2)-(5): 


$$
\begin{gathered}
R M S E_{X}=\sqrt{\frac{\sum_{i=1}^{n}\left[\left(X_{O i}-X_{G C P i}\right)^{2}\right]}{n}} \\
R M S E_{Y}=\sqrt{\frac{\sum_{i=1}^{n}\left[\left(Y_{O i}-Y_{G C P i}\right)^{2}\right]}{n}} \\
R M S E_{X Y}=\sqrt{\frac{\sum_{i=1}^{n}\left[\left(X_{O i}-X_{G C P i}\right)^{2}+\left(Y_{O i}-Y_{G C P i}\right)^{2}\right]}{n}} \\
R M S E_{H}=\sqrt{\frac{\sum_{i=1}^{n}\left[\left(H_{O i}-H_{G C P i}\right)^{2}\right]}{n}}
\end{gathered}
$$

where RMSE is the error, $X_{O i}, Y_{O i}$, and $H_{O i}$ are the value measured in the field, $X_{G P S i}, Y_{G P S i}, H_{G C P i}$ are the coordinates obtained from the TDOM in Pix $4 \mathrm{D}$, and $n$ is the number of checkpoints.

\section{Results and Discussion}

\subsection{Point Cloud Evaluation}

A SfM algorithm was used to restore the camera exposure position and motion trajectory, thereby generating a sparse point cloud. The sparse point cloud was then used for camera calibration, and an MVS algorithm was used to generate a dense point cloud, according to the DSM generation method using reverse distance weight interpolation. The photogrammetric block was processed in Pix4D with the number of 2D key point observations for bundle block adjustment $=12,842,781$, number of 3D points for bundle block adjustment $=4,604,850$, and mean reprojection error of 0.241951 pixels.

Figure 6a shows that, by using the SfM with feature point matching, we can restore each image camera exposure position and UAV trajectory and densify the sparse point cloud. The 3D point clouds contained approximately 154.88 million points, with an average of 592.85 points $/ \mathrm{m}^{3}$. The 3D point cloud data were used to create a mesh network model, and then the inverse distance weight interpolation method was used to generate the DSM, the sharp noise filtering and surface smoothing was processed for DSM. Figure $6 \mathrm{~b}$ shows the overlap of the DOM, with green areas indicating an overlap of more than five images for every pixel. Our study area is green except for the borders, indicating a high degree of overlap. In general, these methods will generate high-quality results so long as the number of key point matches is also sufficient. Red and yellow areas in Figure $6 \mathrm{~b}$ indicate low overlap for which poor results may be generated. 


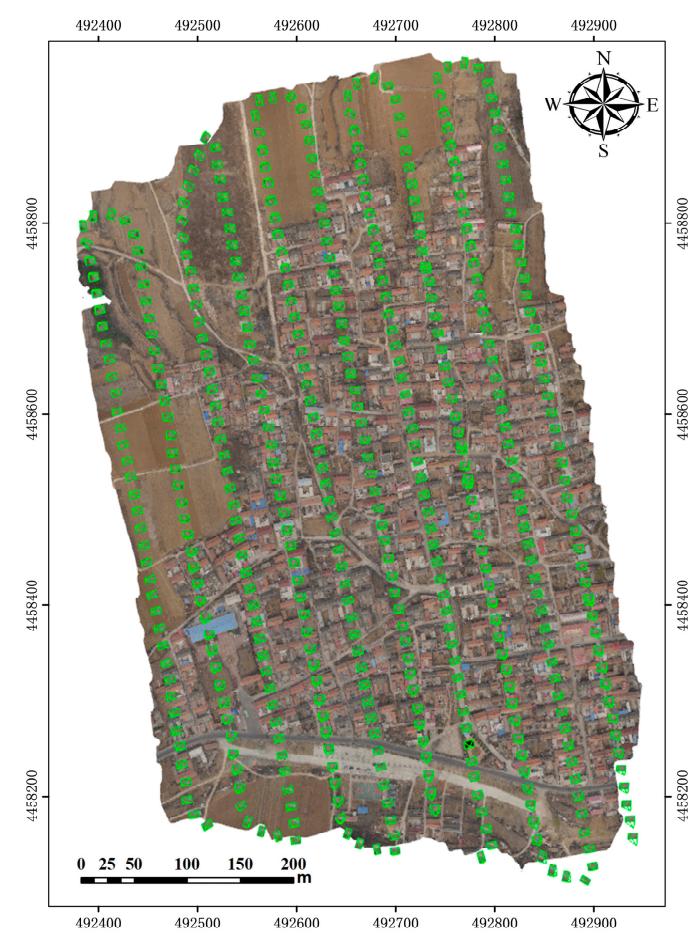

(a)

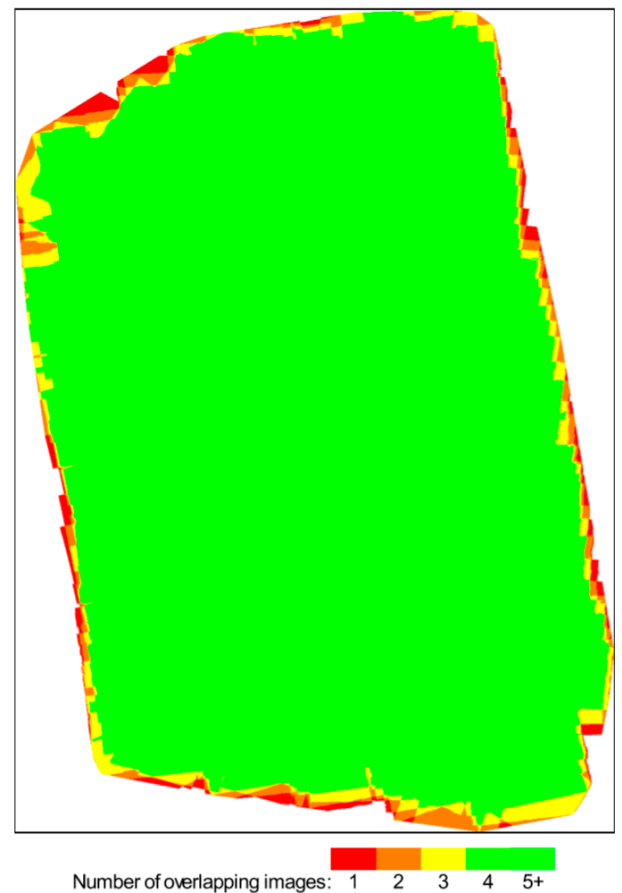

(b)

Figure 6. Images showing (a) restoration of the camera exposure location and UAV trajectory using the SfM algorithm and (b) the overlap of the digital orthophoto map (DOM) with the UAV point cloud; areas masked in green indicate an overlap of more than five images.

\subsection{DSM Revision and TDOM Ortho-Rectification}

Figure 7 shows the original DSM, original DOM, revised DSM, and the DOM generated by the revised DSM, illustrating building outline contours without the tilt obscured. The generated DOM also reduces tilting and shading. A comparison of Figure 7c with Figure 7a reveals that the boundary contours of the four buildings in view are more precise and clearer and the ground height is unified in Figure 7c. Figure 7b shows the DOM generated by the original DSM in which, due to the double projection of the DSM caused by shadowing within the red circles, there is also a double projection within the red circles in the DOM that generated Figure $7 \mathrm{~b}$. Figure $7 \mathrm{~d}$ is the DOM generated by the revised DSM and, as can be seen in the red circles, due to the double-projection phenomenon, double projection of the DOM is essentially eliminated (red circles). Partial elimination of the left and right red circles in the original dual projection may be due to the ground point cloud requiring further processing. This problem can be solved by multi-view image compensation. 


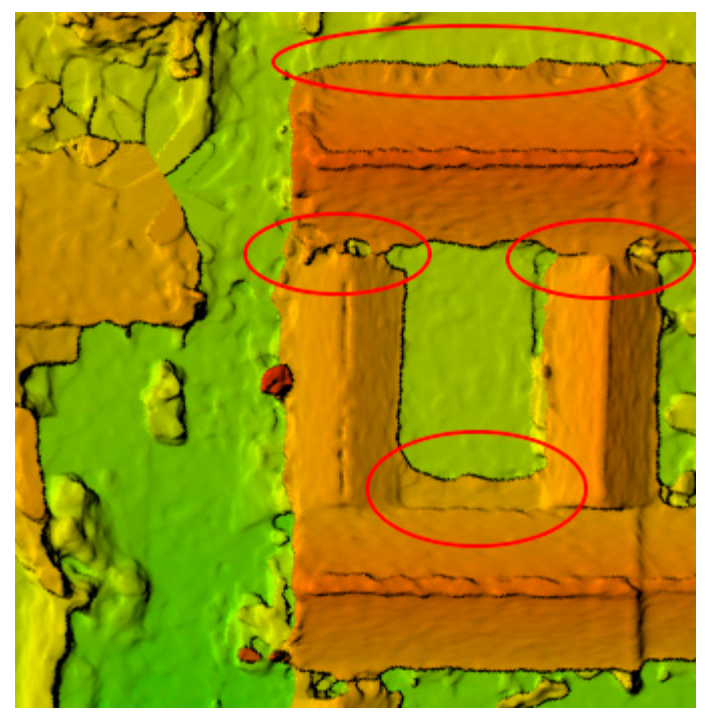

(a)

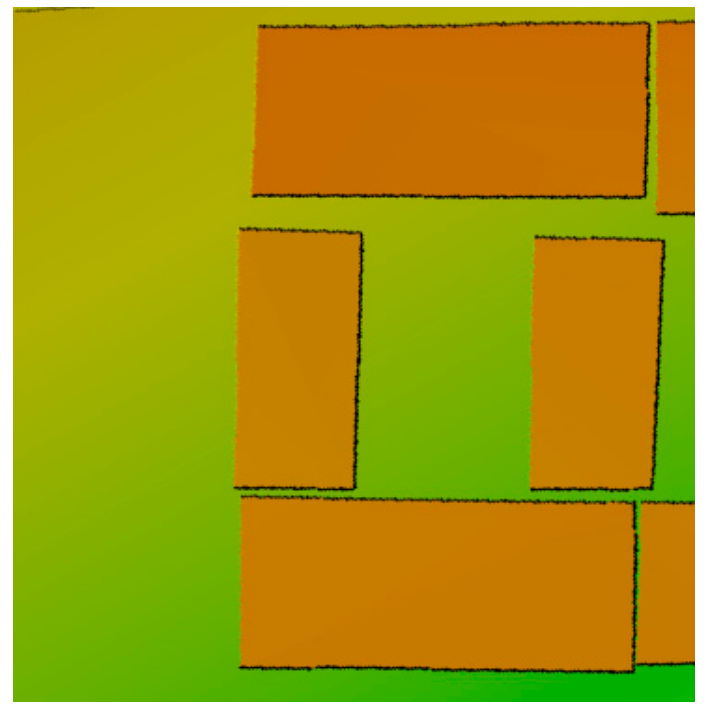

(c)

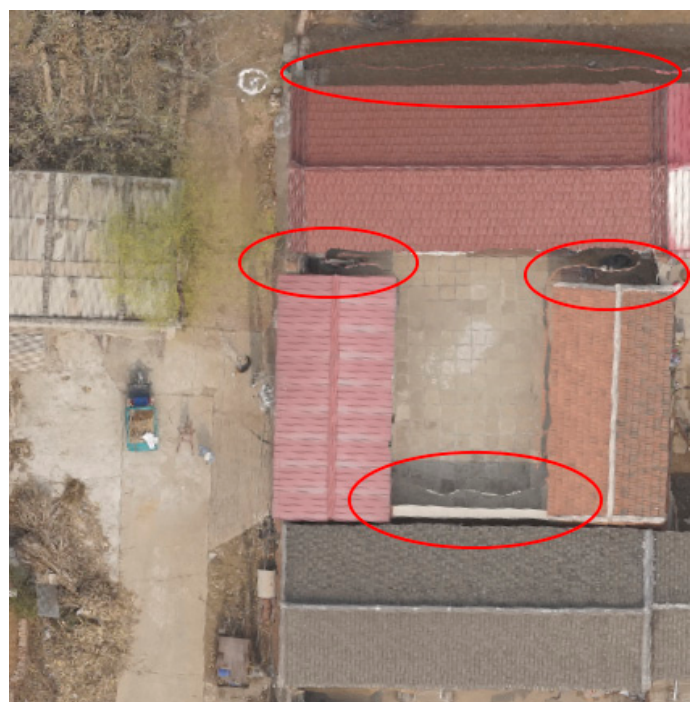

(b)

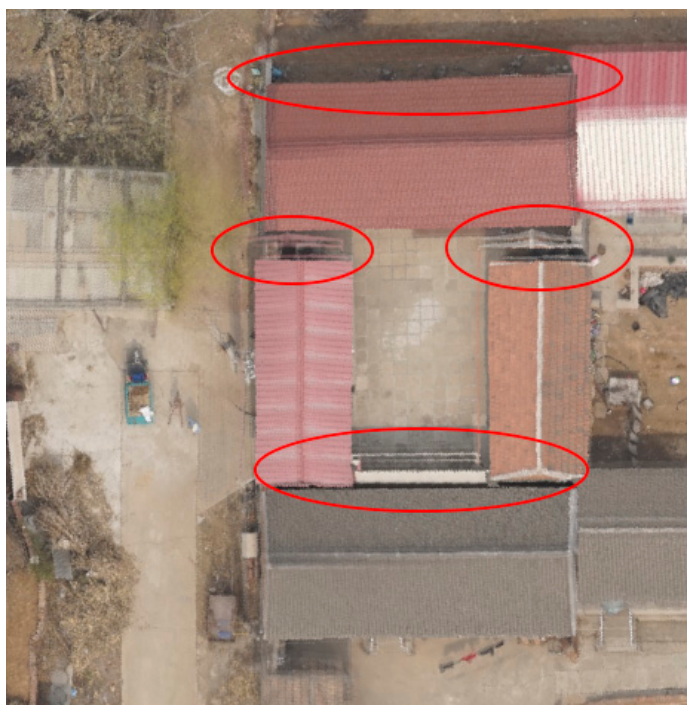

(d)

Figure 7. (a) Original DSM; (b) original DOM; (c) revised DSM; and (d) the DOM generated by the revised DSM.

Figure 8 compares the original DOM and TDOM after multi-view image compensation for test areas A and B. It is clear that, after multi-view image compensation, the double projection shown in the red circle in Figure 8a has been eliminated in Figure 8b, and the vertical view has been restored. In Figure $8 \mathrm{c}$ the buildings are mostly tilted, showing the sides of the houses; however, after the multi-view image compensation method has been employed, the internal structure has eliminated the tilt phenomenon and resulted in a completely vertical surface landscape (Figure 8d). Only the top of the buildings are displayed in Figure $8 \mathrm{~d}$, in which all side surfaces have been avoided, and oblique shadows have been avoided. Thus, through local tests shown in Figure 2 (area A and area B), we find that the multi-view image compensation method can effectively eliminate the double shadow caused by obstructed shadows and eliminate the sides of buildings. This is, therefore, an effective method for solving the obstruction caused by obliquity. However, it should be noted that the test area was chosen to complete the masking compensation because it has a vertical viewing angle in the peripheral image that allows compensation. 


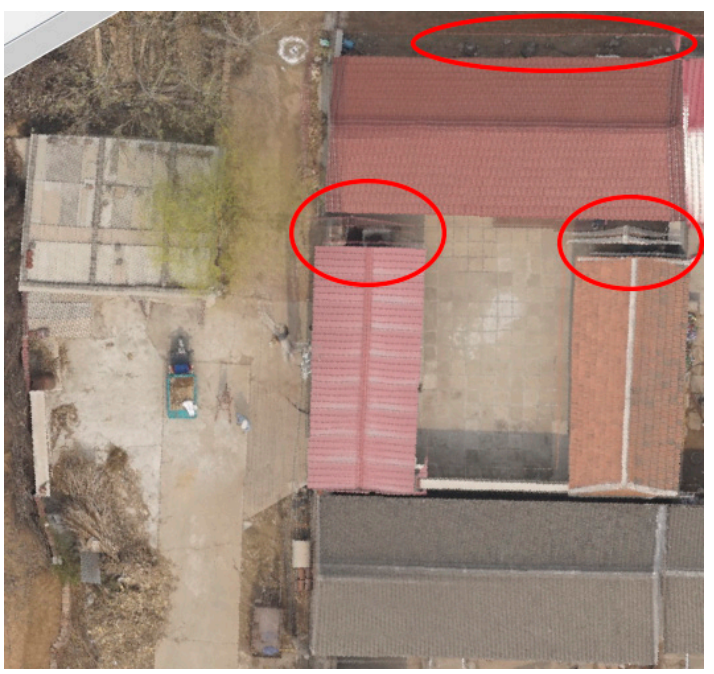

(a)

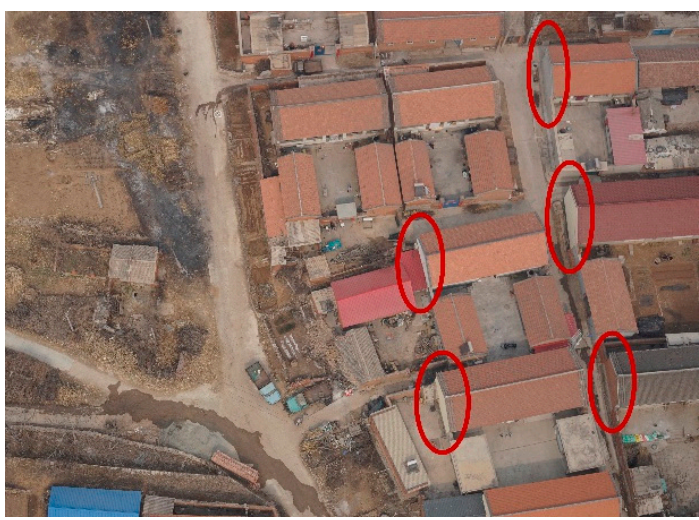

(c)

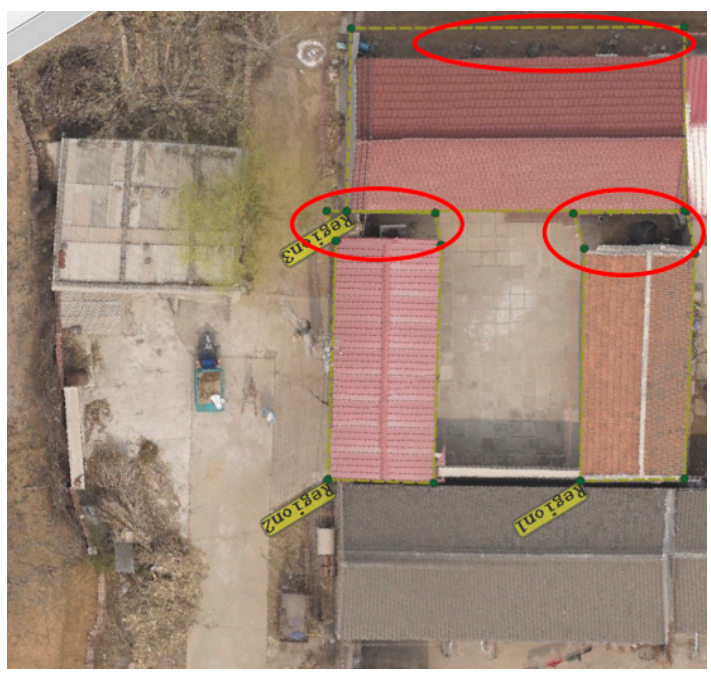

(b)

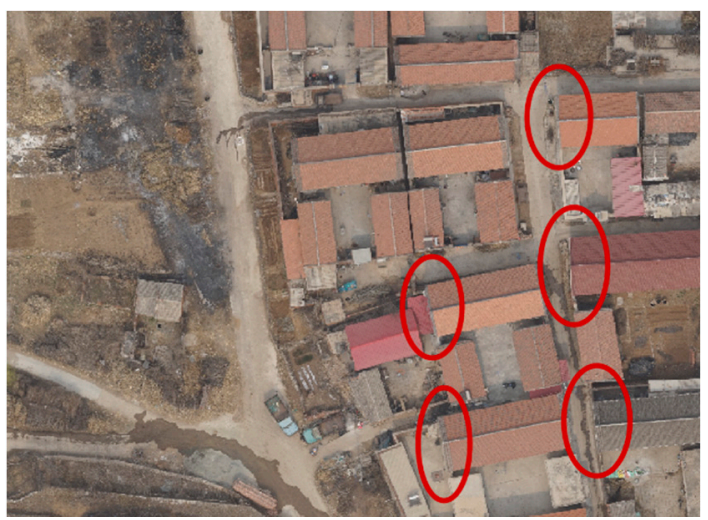

(d)

Figure 8. (a) Original DOM of the test area A; (b) TDOM of the test area A after multi-view image compensation; (c) original DOM of the test area B; and (d) TDOM of the test area B after multi-view image compensation.

\subsection{TDOM Accuracy Evaluation}

Figure 9a shows the final TDOM image, and ten checkpoints were randomly selected and compared with the field measurements (Table 1). The maximum and minimum errors were $0.0674 \mathrm{~m}$ and $0.0173 \mathrm{~m}$, respectively. The plane error of the TDOM checkpoints was $0.0365 \mathrm{~m}$ and the elevation error was $0.0323 \mathrm{~m}$. The generated DSM and TDOM resolution was $0.0166 \mathrm{~m}$. In the work of Uysal et al. [13], the plane and elevation errors were both $0.062 \mathrm{~m}$. Therefore, our method reduced the plane and elevation errors to $<0.05 \mathrm{~m}$. The "digital aerial photogrammetry aerial triangulation specification GB-T23236-2009", which is a national standard valued in China TDOM accuracy evaluation [40], is 7.1 at a scale of 1:500; this specifies plane and elevation error maximum limits of $0.175 \mathrm{~m}$ and $0.15 \mathrm{~m}$, respectively. Our DOM checkpoint calculation results meet these requirements and are, therefore, of high quality. 


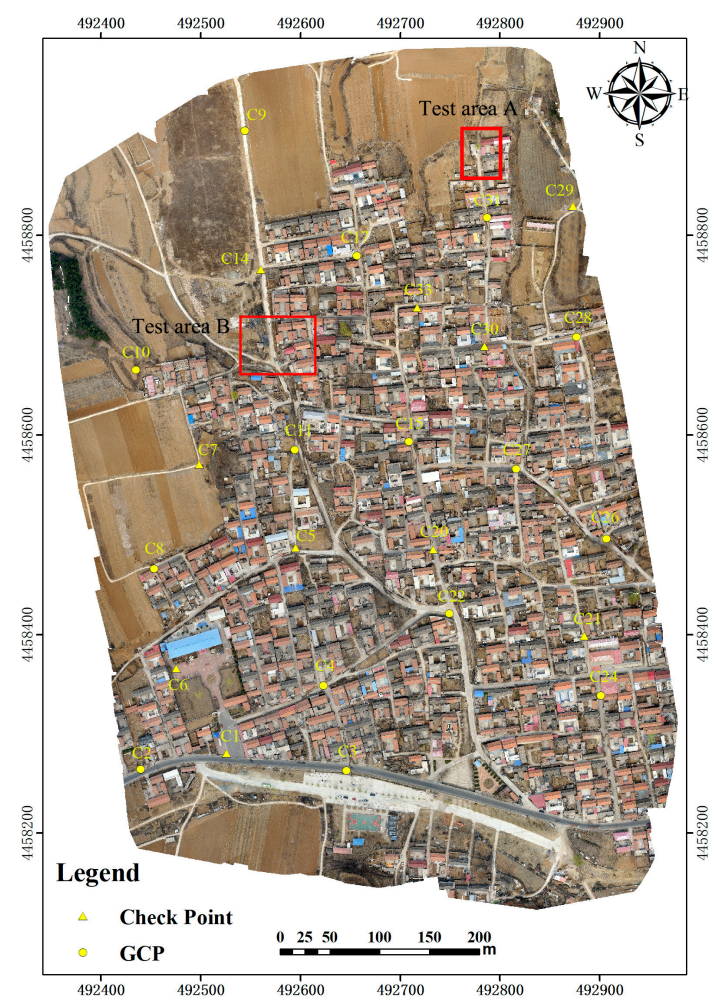

(a)

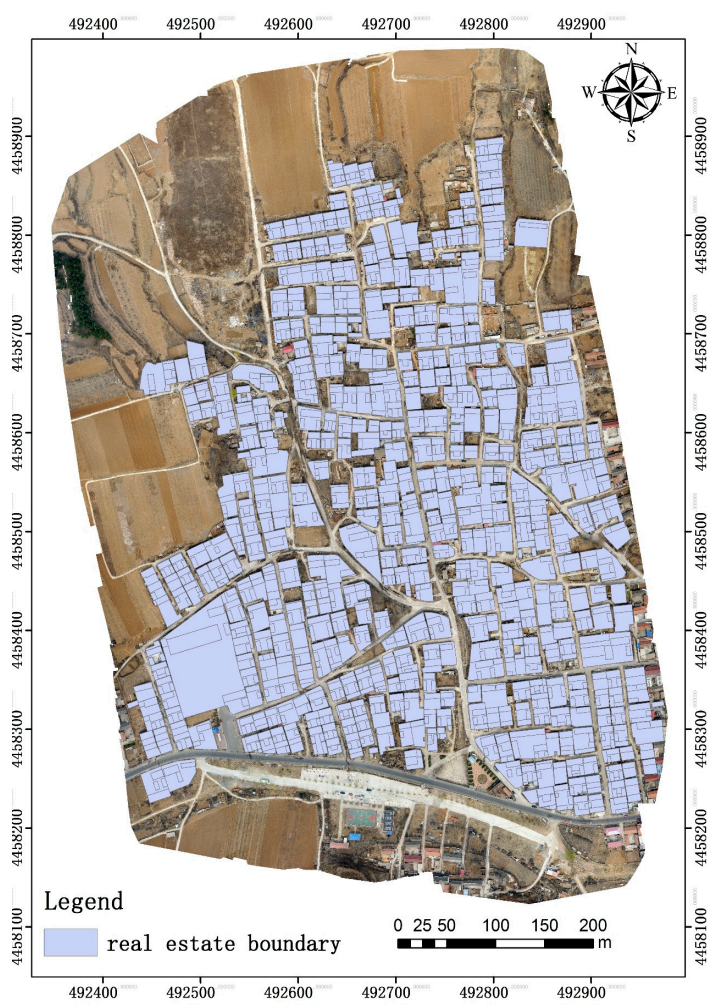

(b)

Figure 9. (a)True digital orthophoto map; (b) Village cadastral map obtained by ArcGIS software vectorization.

Table 1. DOM precision checklist (m).

\begin{tabular}{|c|c|c|c|c|c|c|}
\hline Checking Point & $\Delta X$ & $\triangle Y$ & $\triangle \mathbf{Z}$ & Point RMSE & Plane RMSE & Elevation $R M S E$ \\
\hline $\mathrm{C} 1$ & -0.0079 & 0.0128 & -0.0191 & 0.0150 & & \\
\hline C5 & 0.0171 & 0.0456 & 0.0405 & 0.0487 & & \\
\hline C6 & 0.0094 & 0.0342 & -0.0632 & 0.0354 & & \\
\hline $\mathrm{C} 7$ & -0.0263 & -0.0079 & -0.0409 & 0.0275 & & \\
\hline $\mathrm{C} 14$ & -0.0081 & 0.0107 & -0.0330 & 0.0134 & & \\
\hline $\mathrm{C} 20$ & 0.0011 & 0.0214 & -0.0129 & 0.0215 & & \\
\hline $\mathrm{C} 21$ & 0.0049 & -0.0165 & -0.0273 & 0.0173 & & \\
\hline C29 & 0.0004 & -0.0674 & 0.0056 & 0.0674 & & \\
\hline C 30 & 0.0508 & 0.0309 & -0.0159 & 0.0595 & & \\
\hline $\mathrm{C} 33$ & -0.0176 & -0.0297 & -0.0389 & 0.0345 & 0.0365 & 0.0323 \\
\hline
\end{tabular}

\subsection{Application of Rural Housing Site Confirmation}

The generated TDOM may be applicable to confirming the boundaries of rural residential lands in Beijing. In recent years, China has implemented a nationwide registration of immovable property. An important step in registration is determining the authority of the real estate boundary, which is generally performed using traditional manual mapping. The use of UAV low-altitude remote sensing technology can greatly increase the efficiency, and accuracy of these maps, as well as reduce the costs, associated with producing them. Since confirming the boundaries of rural residential lands requires the determination of precise building boundaries, the boundary of the premises must be accurate, and there must be no lateral or oblique shadows, which reduce imaging accuracy, outside the roof area. This study generated high-precision TDOMs that eliminate the obstruction of shadows and could, therefore, be used to determine the boundaries of rural homestead sites. 
To illustrate the practical applications of the TDOM generated in this study, we vectorized roof footprints manually in ArcGIS 10.2. To achieve this, we referred to the housing boundary in the TDOM, in order to manually create the features for the top surface of the house and each household. The yards were also vectorized, and it was necessary to zoom in on the TDOM during the process to determine that the corner exactly matched the actual houses. The results of this experiment are shown in Figure 9b.

\section{Conclusions}

In this study, we collected high-resolution professional camera images using a multi-rotor UAV in Xishaoqu Village, Miyun County, Beijing. Ground control points were established and measured using the CORS method. We used a SfM algorithm to calculate the camera exposure, camera calibration, and motion trajectory, and MVS intensive matching for generating the 3D point cloud model. High-precision DSMs and DOMs were generated from the point cloud. For shaded areas, we performed textural repair based on the DSM. The use of ortho-rectification in TDOM generation was found to effectively solve the traditional DOM center projection deformation issue, as well as the obscuring of terrain by oblique shadows. The TDOM produced had a high degree of accuracy: a plane error of $0.0365 \mathrm{~m}$ and an elevation error of $0.0323 \mathrm{~m}$, and the generated DSM and TDOM resolution was $0.0166 \mathrm{~m}$. Thus, our results improved on the "digital aerial photogrammetry aerial triangulation specification GB-T23236-2009" 7.1 at a scale of 1:500, which has maximum limits for plane and elevation errors of $0.175 \mathrm{~m}$ and $0.15 \mathrm{~m}$, respectively. As the confirmation of the boundary of rural residential land requires the recovery of precise building boundaries, our methods, which exceed the accuracy required by national standards, may provide a new tool for mapping rural land areas. Using UAVs to collect images and generate TDOMs can greatly reduce the workload related to field-based measurements and improve the accuracy of Beijing real estate registration. Furthermore, the generated TDOM may be widely applicable to land planning, precision agriculture, desertification monitoring, land use surveys, and rural housing registration.

Author Contributions: X.Z. initiated the research and designed the experiments; Y.L. performed experiments, analyzed the data, and wrote most of the paper; G.A. collected the data in the field; Y.Z. (Yi Zhang) improved the English language; and Y.Z. (Yuqiang Zuo) processed the charts and figures in the major revision.

Funding: This research was supported funded by [Ministry of Land and Resources Public welfare industry research funding project] grant number [201511010], and [the Fundamental Research Funds for the Central Universities] grant number [2652017120].

Acknowledgments: The authors would like to thank the editor and the five anonymous reviewers for their helpful feedback.

Conflicts of Interest: The authors declare no conflict of interest.

\section{References}

1. Cao, M.; Bo, Z.; Li, Y. Rapid Production of UAV Imagery without Control Point Data. Bull. Surv. Mapp. 2016, $8,35-38$.

2. Zhao, X. Research and Application of Aerial Camera DOM Generation Technology Based on UAV. Master's Thesis, East China University of Technology, Nanchang, China, 2015.

3. Chen, L.; Zhu, C.; Xu, Q.; Lan, C. The Accuracy Test of the UAV Airborne Water Control Point Deployment Scheme. Surv. Mapp. Sci. 2016, 41, 205-210.

4. Lucieer, A.; Jong, S.M.D.; Turner, D. Mapping landslide displacements using Structure from Motion (SfM) and image correlation of multi-temporal UAV photography. Prog. Phys. Geogr. 2014, 38, 97-116. [CrossRef]

5. Colomina, I.; Molina, P. Unmanned aerial systems for photogrammetry and remote sensing: A review. ISPRS J. Photogramm. Remote Sens. 2014, 92, 79-97. [CrossRef]

6. Toth, C.; Jóźków, G. Remote sensing platforms and sensors: A survey. ISPRS J. Photogramm. Remote Sens. 2016, 115, 22-36. [CrossRef] 
7. Zhang, X. Study on Real Radiography Production Based on UAV Images; China University of Geosciences (Beijing): Beijing, China, 2016.

8. He, J.; Li, Y.; Lu, H.; Ren, Z. Study on the Quality Assessment and Geometric Processing of Drone Imaging. Bull. Surv. Mapp. 2010, 4, 22-24.

9. Agüera-Vega, F.; Carvajal-Ramírez, F.; Martínez-Carricondo, P. Assessment of photogrammetric mapping accuracy based on variation ground control points number using unmanned aerial vehicle. Measurement 2017, 98, 221-227. [CrossRef]

10. Mesascarrascosa, F.J.; Rumbao, I.C.; Berrocal, J.A.B.; Porras, A.G. Positional Quality Assessment of Orthophotos Obtained from Sensors Onboard Multi-Rotor UAV Platforms. Sensors 2014, 14, 22394-22407. [CrossRef] [PubMed]

11. Ruzgienè, B.; Berteška, T.; Gečyte, S.; Jakubauskienè, E. The surface modelling based on UAV Photogrammetry and qualitative estimation. Measurement 2015, 73, 619-627. [CrossRef]

12. Cui, Y.; Zheng, X.; Hu, K.; Zhang, X.; Chen, P. The Application of UAV Low-altitude Remote Sensing in the Information Acquisition Process of Rural Homesteads. In Proceedings of the 7th National Congress of the Chinese Natural Resources Society 2014 Academic Annual Meeting, Zhengzhou, China, 9-11 October 2014.

13. Shahbazi, M.; Sohn, G.; Théau, J.; Menard, P. Development and Evaluation of a UAV-Photogrammetry System for Precise 3D Environmental Modeling. Sensors 2015, 15, 27493-27524. [CrossRef] [PubMed]

14. Lucieer, A.; Turner, D.; King, D.H.; Robinson, S.A. Using an Unmanned Aerial Vehicle (UAV) to capture micro-topography of Antarctic moss beds. Int. J. Appl. Earth Obs. Geoinf. 2014, 27, 53-62. [CrossRef]

15. Habib, A.F.; Kim, E.M.; Kim, C.J. New Methodologies for True Orthophoto Generation. Photogramm. Eng. Remote Sens. 2015, 73, 25-36. [CrossRef]

16. Gao, M.; Xu, X.; Klinger, Y.; Woerd, J.V.D.; Tapponnier, P. High-resolution mapping based on an Unmanned Aerial Vehicle (UAV) to capture paleoseismic offsets along the Altyn-Tagh fault, China. Sci. Rep. 2017, 7, 8281. [CrossRef] [PubMed]

17. Uysal, M.; Toprak, A.S.; Polat, N. DEM generation with UAV Photogrammetry and accuracy analysis in Sahitler hill. Measurement 2015, 73, 539-543. [CrossRef]

18. Westoby, M.J.; Brasington, J.; Glasser, N.F.; Hambrey, M.J.; Reynolds, J.M. 'Structure-from-Motion' photogrammetry: A low-cost, effective tool for geoscience applications. Geomorphology 2012, 179, 300-314. [CrossRef]

19. Ai, M.; Hu, Q.; Li, J.; Wang, M.; Yuan, H.; Wang, S. A Robust Photogrammetric Processing Method of Low-Altitude UAV Images. Remote Sens. 2015, 7, 2302-2333. [CrossRef]

20. Fan, B.; Yang, Q.; Bao, Q.; Xu, Z. The Assessment of Lumen 1:1000 True Radiographic Production and Its Application in the Village Cadastral Survey. Bull. Surv. Mapp. 2016, 10, 76-80.

21. Li, H.; Zhong, C.; Huang, X. A fast and effective approach to generate true orthophoto in built-up area. Sens. Rev. 2011, 31, 341-348.

22. de Oliveira, H.C.; Dal Poz, A.P.; Galo, M.; Habib, A.F. Surface Gradient Approach for Occlusion Detection Based on Triangulated Irregular Network for True Orthophoto Generation. IEEE J. Sel. Top. Appl. Earth Obs. Remote Sens. 2018, 11, 443-457. [CrossRef]

23. Svennevig, K.; Guarnieri, P.; Stemmerik, L. From Oblique Photogrammetry to a 3D Model—Structural Modeling of Kilen, Eastern North Greenland; Pergamon Press, Inc.: Oxford, UK, 2015; pp. 120-126.

24. Zhu, Q.; Yu, J.; Du, Z.; Zhang, Y. Original Object-Oriented True Image Correction Methods. J. Wuhan Univ. (Inf. Sci. Ed.) 2013, 38, 757-760.

25. Marsella, M.; Nardinocchi, C.; Proietti, C.; Daga, L.; Coltelli, M. Monitoring Active Volcanos Using Aerial Images and the Orthoview Tool. Remote Sens. 2014, 6, 12166-12186. [CrossRef]

26. Harvey, M.C.; Rowland, J.V.; Luketina, K.M. Drone with thermal infrared camera provides high resolution georeferenced imagery of the Waikite geothermal area, New Zealand. J. Volcanol. Geotherm. Res. 2016, 325, 61-69. [CrossRef]

27. Tong, X.; Liu, X.; Chen, P.; Liu, S.; Luan, K.; Li, L.; Liu, S.; Liu, X.; Xie, H.; Jin, Y. Integration of UAV-Based Photogrammetry and Terrestrial Laser Scanning for the Three-Dimensional Mapping and Monitoring of Open-Pit Mine Areas. Remote Sens. 2015, 7, 6635-6662. [CrossRef] 
28. Johnson, K.; Nissen, E.; Saripalli, S.; Arrowsmith, J.R.; Mcgarey, P.; Scharer, K.; Williams, P.; Blisniuk, K. Rapid mapping of ultrafine fault zone topography with structure from motion. Geosphere 2014, 10, 969-986. [CrossRef]

29. Morelan, A.E., III; Trexler, C.C.; Oskin, M.E. Rapid documentation of earthquake surface displacements using structure from motion photogrammetry. In Proceedings of the AGU Fall Meeting, San Francisco, CA, USA, 14-18 December 2015.

30. Rippin, D.M.; Pomfret, A.; King, N. High resolution mapping of supra-glacial drainage pathways reveals link between micro-channel drainage density, surface roughness and surface reflectance. Earth Surf. Process. Landf. 2015, 40, 1279-1290. [CrossRef]

31. Dąbski, M.; Zmarz, A.; Pabjanek, P.; Korczak-Abshire, M.; Karsznia, I.; Chwedorzewska, K. UAV-based detection and spatial analyses of periglacial landforms on Demay Point (King George Island, South Shetland Islands, Antarctica). Geomorphology 2017, 290, 29-38. [CrossRef]

32. Ely, J.C.; Graham, C.; Barr, I.D.; Rea, B.R.; Spagnolo, M.; Evans, J. Using UAV acquired photography and structure from motion techniques for studying glacier landforms: Application to the glacial flutes at Isfallsglaciären. Earth Surf. Process. Landf. 2016, 42, 877-888. [CrossRef]

33. Rokhmana, C.A. The Potential of UAV-based Remote Sensing for Supporting Precision Agriculture in Indonesia. Procedia Environ. Sci. 2015, 24, 245-253. [CrossRef]

34. Yang, G.; Li, C.; Wang, Y.; Yuan, H.; Feng, H.; Xu, B.; Yang, X. The DOM Generation and Precise Radiometric Calibration of a UAV-Mounted Miniature Snapshot Hyperspectral Imager. Remote Sens. 2017, 9, 642. [CrossRef]

35. Sonnemann, T.; Ulloa Hung, J.; Hofman, C. Mapping Indigenous Settlement Topography in the Caribbean Using Drones. Remote Sens. 2016, 8, 791. [CrossRef]

36. Rusnák, M.; Sládek, J.; Kidová, A.; Lehotský, M. Template for high-resolution river landscape mapping using UAV technology. Measurement 2018, 115, 139-151. [CrossRef]

37. Chen, N.Y.; Chen, L.C.; Rau, J.Y. True Orthophoto Generation of Built-Up Areas Using Multi-View Images. Photogramm. Eng. Remote Sens. 2002, 68, 581-588.

38. Jiang, W.; Yuan, P.; Tian, W.; Xiao, Y. Unified Method of Coordinate Benchmarks in Regional CORS Network. J. Wuhan Univ. (Inf. Sci. Ed.) 2014, 39, 566-570.

39. Chang, B.; Chen, Y. Basic principles and methods of digital differential correction. J. Surv. Mapp. 1983, 3 , 31-40.

40. National Mapping Agency. National Bureau of Surveying and Mapping CHZ3004-2010 Low-Level Digital Aerial Photogrammetry Field Practice; National Mapping Agency: Madison, WI, USA, 2010. 